\title{
SOSIALISASI MENGOPERASIKAN TEKNOLOGI INFORMASI KEPADA IBU-IBU PKK PANGKALAN JATI BARU DEPOK
}

\author{
Ana Rusmardiana ${ }^{1)}$, Atikah²) \\ ${ }^{12}$ Program Studi Informatika, Fakultas Teknik dan Ilmu Komputer, Universitas Indraprasta PGRI
}

\begin{abstract}
Abstrak
Di setiap kelurahan terdapat sebuah wadah yang turut membantu dalam menuntaskan visi dan misi yakni salah satunya PKK (Pemberdayaan Kesejahteraan Keluarga). Dalam Kegiatannya mereka harus turut menunjang apa yang merupakan program kerja yang harus dijalani atau yang dikenal dengan 10 program kerja. (Peraturan Menteri Dalam Negeri No 1Tahun 2013, Pasal 5). Untuk menunjang kegiatan tersebut kadangkala diperlukan laporanlaporan akan aktivitas yang telah dilakukan baik dalam berbentuk artikel ataupun presentasi. Oleh karenanya diperlukan keterampilan dan pengetahuan bagaimana mengoperasikan teknologi informasi seperti word, exel dan power point mengingat PKK ini merupakan salah satu bagian dari organisasi kemasyakatan yang mewadahi para kaum wanita, dan dilapangan umumnya kaum wanita yang tergabung kebanyakan adalah ibu-ibu rumah tangga yang jarang sekali berkontabulasi dengan teknologi informasi seperti notebook dan sebagainya.
\end{abstract}

Kata Kunci: Word, Power Point, Excel

\begin{abstract}
Every district has forum that helps in completing the vision and mission, one of which is the PKK (Family Welfare Empowerment). In The activities they have contributed to what constitutes a work program that should be lived, known as 10 work program(Regulation of the Minister of Interior No. 1-year of 2013, Article 5). To support these activities sometimes required reports of activities that have performed well in the form of articles or presentations. Therefore skills and knowledge are needed to operate information technology such as word, exel and power point, considering that this PKK is a part of a community organization that accommodates women, and in general the women who are members are mostly housewives who rarely contablating with information technology such as notebooks and so on.
\end{abstract}

Keyword: Word, Power Point, Excel

Correspondence author: Ana Rusmardiana, ana.irawan93@gmail.com, Indonesia

\section{PENDAHULUAN}

Hampir semua aspek tidak terlepas pada kepentingannya dalam hal teknologi informasi baik diperuntukan kepada anak-anak, remaja maupun orang dewasa, dalam kehidupan sosial bermasyarakat, dunia pendidikan ataupun dunia kerja dan sebagainya. Seperti halnya sofware yang termasuk dalam microsoft office yaitu aplikasi yang 
digunakan untuk membuat berbagai jenis dokumen, baik dokumen berupa artikel, surat, presentasi ataupun untuk perhitungan statistik. Cukup banyak aplikasi-aplikasi yang masuk kedalam golongan microsoft office, di antaranya adalah microsoft word, microsoft excel dan microsoft powerpoint.

Menurut Suryana Taryana, Koesheryatin [2014:9] Microsoft word merupakan program aplikasi dari microsoft office yang biasa sering digunakan untuk pengelolahan teks, pengelolahan dokumen, laporan dan lain sebagainya yang cukup lengkap dan lebih otomatis. Bahkan perintah dan fungsi yang disediakan oleh software ini menunjang berbagai keperluan mulai dari pengetikan atau penyusunan naskah biasa, laporan, surat kabar sampai dengan fax. Oleh karenanya microsoft word adalah merupakan aplikasi yang sangat sering dipergunakan terutama dalam pembuatan dokumen apakah berupa catatan, surat, dokumen dalam bentuk artikel dan sebagainya.

Aplikasi lainnya yang juga sering digunakan oleh masyarakat adalah aplikasi yang diperuntukan untuk membuat perhitungan seperti kalkulator ataupun perhitungan seperti statistik dengan memiliki data yang lebih komplek dikenal dengan aplikasi microsoft excel. Didalam artikelnya Suryana Taryana, Koesheryatin [2014:95] dikatakan microsoft excel adalah program perhitungan yang sangat populer di Indonesia. Saat ini cukup banyak pengguna microsoft excel yang hanya menggunakan program ini untuk mengetik tabel, padahal di dalam microsoft excel tersedia banyak fasilitas untuk memaksimalkan pembuatan laporan dalam bentuk tabel dan memecahkan banyak perhitungan yang rumit.

Aplikasi lain yang akan dibahas dan tidak kalah menarik adalah aplikasi microsoft powerpoint yang menawarkan kemudahan-kemudahan dalam membuat bahan presentasi yang berbentuk elektronis.

Ketiga aplikasi tersebut diatas secara umum sangatlah efisien dan sangat cepat dalam pengoperasiannya dan banyak digunakan oleh lapisan masyarakat. Seperti halnya ibu-ibu yang termasuk dalam program Pemberdayaan Kesejahteraan Keluarga atau yang dikenal dengan ibu-ibu PKK, perlu kiranya menguasai ketiga office tersebut. Selain ibuibu PKK memiliki keterampilan dalam bersosialisasi namum mereka juga memerlukan pengetahuan-pengetahuan lainnya seperti halnya dalam pengoperasiannya ketiga office tersebut.

Berdasarkan peraturan daerah kota Depok No.6 Tentang Pembentukan Kecamatan di Kota Depok (2010:7) terdapat 11 (sebelas) Kecamatan, salah satunya adalah Kecamatan Cinere yang memiliki 4 (empat) wilayah kerja administrasi dalam bentuk Kelurahan dan salah satunya adalah Kelurahan Pangkalan Jati Baru. Pada umumnya disetiap kelurahan terdapat sebuah wadah yang turut membantu dalam menuntaskan visi dan misi yakni salah satunya PKK (Pemberdayaan Kesejahteraan Keluarga).

Menurut Peraturan Menteri Dalam Negeri No 1Tahun 2013 Bab I pasal 1 (2013:2), Gerakan Pemberdayaan dan Kesejahteraan Keluarga, selanjutnya disingkat Gerakan PKK adalah gerakan nasional dalam pembangunan masyarakat yang tumbuh dari bawah yang pengelolaannya dari, oleh dan untuk masyarakat, menuju terwujudnya keluarga yang beriman dan bertaqwa kepada Tuhan Yang Maha Esa, berakhlak mulia dan berbudi luhur, sehat sejahtera, maju dan mandiri, kesetaraan dan keadilan gender serta kesadaran hukum dan lingkungan.

Dikutip dari Debora Meriska dkk (2018) Pembinaan Kesejahteraan Keluarga yang disingkat PKK, adalah organisasi kemasyarakatan yang memberdayakan wanita untuk turut berpartisipasi dalam pembangunan Indonesia sebagai organisasi publik yang mempunyai unsur-unsur kelembagaan dari pusat, propinsi, kabupaten/kota, kecamatan, desa dan kelurahan. Seperti halnya kaum wanita yang termasuk dalam PKK keluran 
Pangkalan Jati Baru, Depok umumnya mereka ibu-ibu yang tidak bekerja atau sebagian besar adalah ibu rumah tangga dan untuk pendidikan mereka paling banyak adalah lulusan SMA. Sebahagian dari mereka masih rentang dan masih tertinggal dalam hal penggunaan teknologi informasi seperti halnya dalam mengoperasikan office.

Sebagai bagian dari PKK mereka harus turut menunjang apa yang merupakan program kerja yang harus dijalani atau yang dikenal dengan 10 program kerja. Dalam pelaksanaan program kerja tersebut, mereka harus mengerjakan dalam kelompoknya dan kadangkala para anggota yang masuk dalam PKK ini diminta untuk membuat program PKK serta melaporkan program tersebut dalam bentuk microsoft word dengan menggunakan tabel ataupun perhitungan yang dapat digunakan pada microsoft excel ataupun dalam presentasi menggunakan microsoft powerpoint.

Dengan memperhatikan permasalahan tersebut, solusi yang ditawarkan dan yang diinginkan oleh sebagian besar dari ibu-ibu PKK Pangkalan Jati Baru Depok, adalah sebagai berikut:

1. Mensosialisasikan tentang bagaimana pentingnya pengetahuan dalam pengoperasian microsoft office baik dalam keikutsertaannya diwadah PKK juga sebagai bagian dari tugas orangtua dalam membantu kesejahtraan pengetahuan anaknya ataupun untuk diri sendiri.

2. Pemberian gambaran umum tentang microsoft word, powerpoint dan excel.

3. Memberikan kesempatan untuk mencoba dalam pembuatan dokumen, menyimpan, membuat perhitungan dan membuat presentasi bersasarkan kreasinya masing-masing.

Target dan luaran yang ingin dicapai dalam pelaksanaan pengabdian masyarakat yang kami lakukan melalui sosialisasi dan pembelajaran adalah:

1. $\pm 70 \%$ dari ibu-ibu yang masuk dalam organisasi PKK Pangkalan Jati Baru Depok mengetahui maksud dan fungsi pengetahuaan dibidang teknologi terutama dalam pengoperasian ketiga office yang masuk kedalam microsoft office yaitu microsoft word, microsoft power poin dan microsoft excel.

2. Ibu-Ibu PKK Pangkalan Jati Baru dapat memanfaatkan dan mengoperasikam microsoft office word secara efektif dalam pembuatan berbagai laporan ataupun tulisan-tulisan.

3. Dapat membuat tabel dan perhitungan secara baik berkaitan dengan aktivitas ibu-ibu PKK dikelurahan Pangkalan jati Baru Depok.

\section{METODE PELAKSANAAN}

Metode pelaksanaan pengabdian masyarakat kepada para ibu-ibu PKK Pangkalalan Jati Baru Depok, dilakukan dengan kegiatan sebagai berikut:

1. Tahap Persiapan

Kami melakukan kunjungan kelokasi Kelurahan Cinere-Depok, untuk selanjutnya oleh pihak Kelurahan kami dipertemukan dengan beberapa ibu-ibu PKKnya dan salah satunya adalah pengurus PKK Pangkalan Jati Baru Depok. Dalam pertemuan dikelurahan Cinere terutama beberapa pengurus PKK Pangkalan Jati Baru, mereka meminta agar diberikan pelatihan ataupun pembelajaran berkaitan dengan penggunaan office mengingat sebahagian dari ibu-ibu PKK tersebut masih awam dan masih memerlukan tambahan pengetahuan tersebut. 
2. Tahap Pengajuan usulan.

Langkah selanjutnya tim kami melakukan pengajuan materi yang akan kami sajikan sesuai permintaan pengurus PKK Pangkalan Jati Baru Depok serta memohon kesediaan waktu serta tempat pelaksanaan.

3. Tahap Pelaksanaan

Metode yang digunakan dalam pelaksanaan kegiatan pengabdian masyarakat yaitu berupa sosialisasi, pelatihan dan pendampingan.

a. Sosialisasi

Tim kami melakukan sosialisasi kepada ibu-ibu PKK Pangkalan Jati Baru tentang arti penting dan maksud pengetahuan micrfosoft office terutama pada 3 aplikasi yang masuk dalam office tersebut.

b. Pembelajaran

Pembelajaran disini dimaksudkan adalah demontrasi langsung, bagaimana seharusnya dilakukan pada saat sebelum pengetikan, pengeditan, fitur-fitur yang harus diperhatikan, melakukan perhitungan, membuat presentasi yang benar dan sebagainya.

c. Pendampingan

Dalam tahap ini kami membagi menjadi dua bagian yakni salah satu dari kami mendemontasikan dan sisanya dari kami melakukan pendampingan pada ibu-ibu dalam mengoperasikan situs-situs yang ada pada word, excel maupun power point dibeberapa notebook mereka, hal ini kami lakukan secara bergantian agar mereka tidak jenuh sekaligus pembagian tugas dari kelompok kami.

d. Tahap Evaluasi

Evaluasi ini dilakukan untuk mengukur tingkat keberhasilan ataupun mengertinya seseorang akan materi dan demontrasi yang mereka lakukan. Hasil evaluasi dapat dijadikan masukan dalam menentukan kegiatan selanjutnya. Dalam hal ini evaluasi dilakukan dngan cara memberikan soal kasus seperti tindakan-tindakan awal yang perlu dilakukan sebelum membuat dokumen, selanjutnya diinstruksikan untuk membuat kalimat sebanyak tiga paragraf untuk selanjutnya diubah menjadi tulisan seperti dalam surat kabar, membuat perhitungan akan suatu nilai tambahan, pengurangan, pengkalian, membuat presentasi sendiri dengan menggunakan fitur-fitur yang ada dan sebagainya.

\section{HASIL DAN PEMBAHASAN}

Di awal kegiatan, kami mengajukan izin untuk melakukan pengabdian masyarakat pada sebuah Kelurahan terutama kepada ibu-ibu PKK yang masuk dalam wilayah Kelurahan Cinere-Depok. Pada saat kunjungan tim kami memohon kerjasama sebagai mitra pada salah satu perkumpulan ibu-ibu PKK yang secara kebetulan dilokasi tersebut, tim kami dipertemukan dengan beberapa pengurus PKK Pangkalan Jati Baru-Depok. 


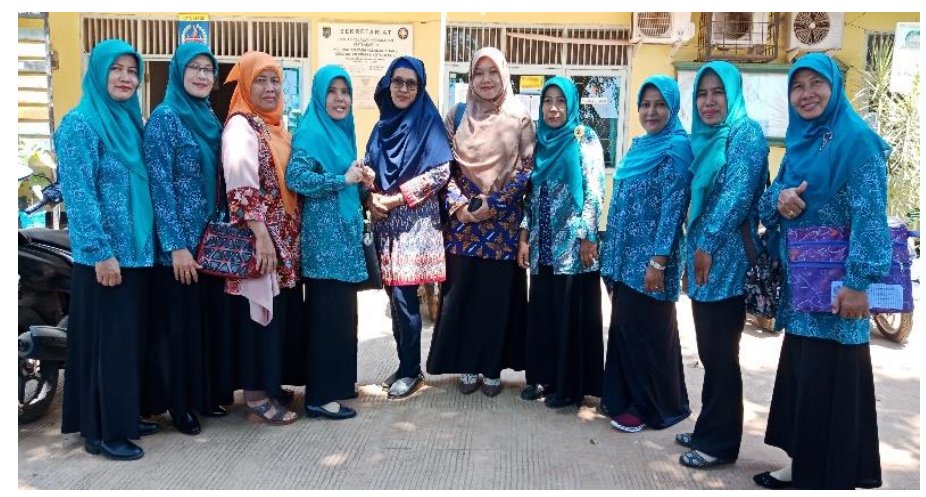

Gambar 1 Ibu-Ibu dan pengurus PKK Pangkalan Jati Baru

Dalam pertemuan tersebut mayoritas dari pengurus PKK Pangkalan Jati Baru Depok meminta agar mereka diberikan pelatihan yang berhubungan dengan office yaitu word, excel dan power point. Mereka beralasan bahwa didalam pengurusan maupun anggotanya masih banyak yang mengalami kesulitan dalam membuat tulisan, membuat perhitungan berkaitan dengan pelaporan-pelaporan yang harus mereka buat serta didalam mempresentasikan suatu rancangan kegiatan ataupun suatu aktivitas.

Dipertemuan selanjutnya tim kami mengajukan proposal kepada pengurus PKK Pangkalan Jati Baru_Depok dengan tema "Sosialisasi Mengoperasikan Teknologi Informasi Kepada Ibu-Ibu PKK Pangkalan Jati Baru Depok". Sekaligus memohon kesediaan waktu dan tempat pelaksanaan pengabdian masyarakat ini.

Pada pelaksanaan abdimas dihari pertama, dimulai dengan pembukaan dengan memperkenalkan kelompok tim, kemudian dilanjutkan dengan sambutan dari Ibu Camat Cinere setempat dan perwakilan dari mitra.

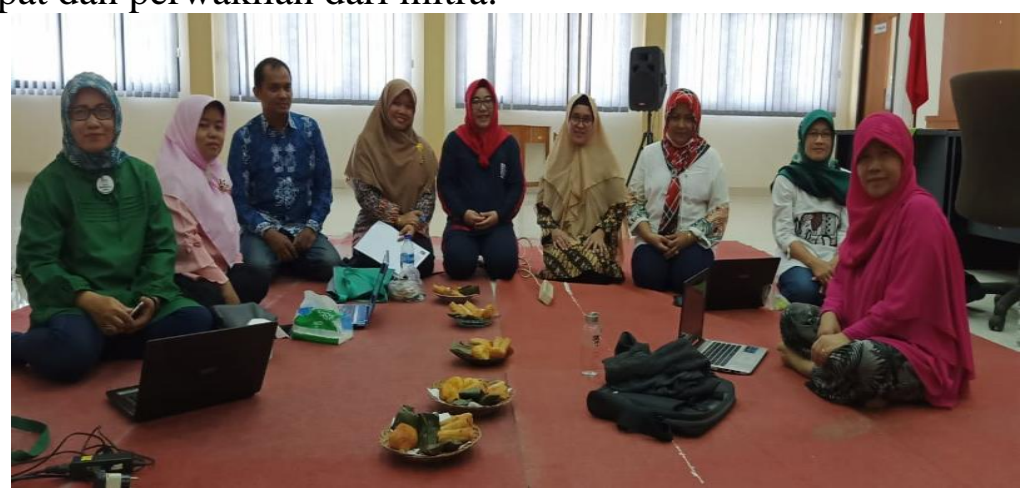

Gambar 2. Sambutan Ibu Camat Cinere

Untuk selanjutnya dimulailah dari pelaksanaan abdimas yakni dengan mensosialisasikan kepada peserta tentang teknologi informasi melalui pengetahuan microsoft office yaitu word, power point dan excel. Dimaksudkan untuk mengetahui sejauhmana pengetahuan para peserta (ibu-ibu PKK Pangkalan Jati Baru Depok) sehingga dapat membuat gambaran kepada tim kami darimana atau materi-materi apa saja yang perlu kami berikan.

Dari hasil sosialisasi diperoleh hasil hampir diperkirakan hanya $10 \%$ yang mengerti dan dapat memanfaatkan sofware (word, excel, powerpoint) tersebut dan itupun hanya beberapa item saja yang dapat dilakukannya, selebihnya mereka harus didampingi dan dibimbing . Dari sisanya yang daro $10 \%$ tersebut mereka menyatakan bahwa selama ini semua berkaitan dengan pembuatan dokumen dal sebagainya dilakukan dengan meminta tolong anak-anaknya atau biro jasa. 
Pelaksanaan pada tatap muka pertama selain melakukan sosialisasi tersebut diatas, tim kami melakukan pelatihan word dan power point melalui demonstrasi, praktek langsung serta tanya jawab. Dalam pelaksanaannya membutuhkan waktu yang cukup lama dan penuh kesabaran.

Di dalam pertemuan pertama yaitu pelatihan word didemonstrasikan tentang beberapa aspek yang perlu dilakukan sebelum membuat suatu tulisan seperti mengatur batas-batas kertas, ukuran kertas, jenis tulisan, after dan before (Page Layout), menentukan jarak, jenis tulisan (Home), membuat kolom, mail merge dan sebagainya. Sementara untuk pelatihan maupun pembelajaran power point dipresentasikan bagaimana membuat presentasi yang baik, menarik dan sebagainya.

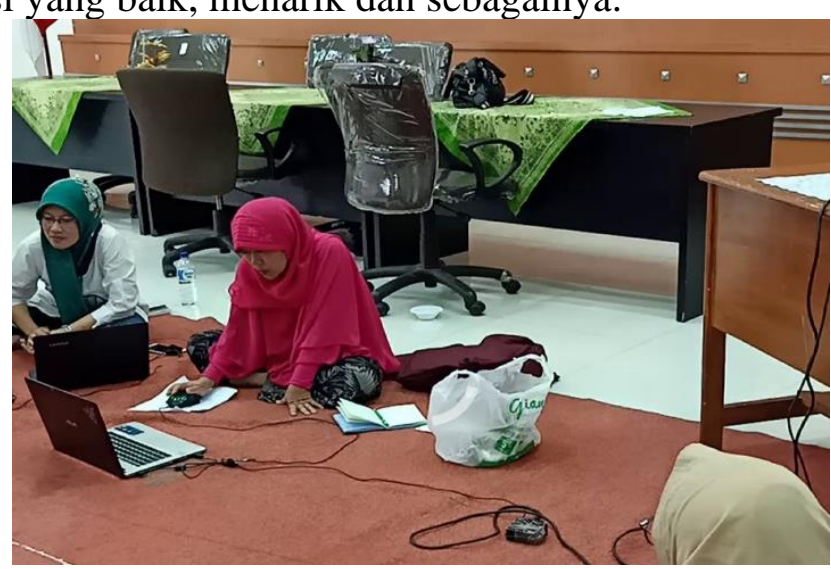

Gambar 3. Aktivitas peserta abdimas 1

Pelaksanaan ditatap muka kedua, mengulang kembali dalam pengoperasian word, power point dan selanjutnya pelatihan excel. Pengulangan kembali pembahasan word maupun power point, dimaksudkan agar para ibu-ibu PKK Pangkalan Jati Baru tidak lupa, dan juga dimaksudkan untuk mengetahui sejauh mana pelatihan yang kami berikan sebelumnya dapat dipahami oleh mereka.

Pada pelatihan selanjutnya tentang Excel. Sama seperti semula pada saat pelatihan word dan excel yaitu tentang apa-apa saja yang perlu diperhatikan sebelum membuat suantu naskah ataupun kegiatan. Selanjutnya dilakukan demonstrasi membuat tabel, mencopy, membuat sel/ range, membuat satuan hitungan dalam rupiah ataupun waktu, perhitungan cepat menggunakan sum, if, Average dan sebagainya.

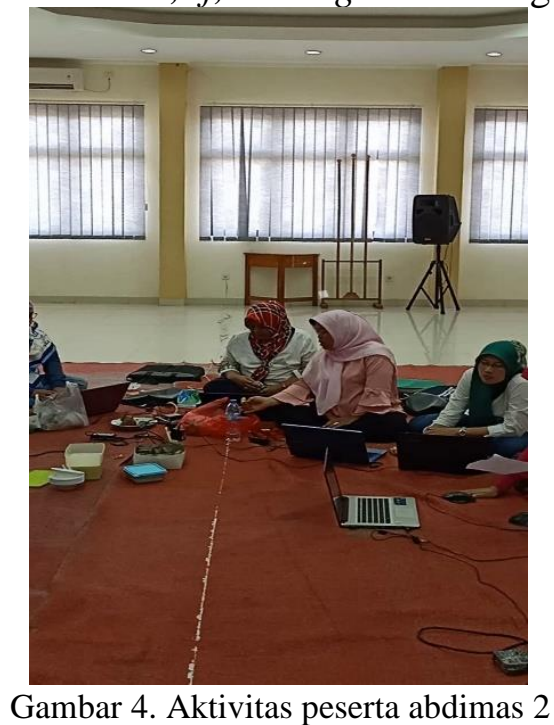


Secara umum kegiatan dapat dikatakan berhasil. Hal ini diindikasikan dengan adanya ketertarikan dalam memperhatikan yang dilakukan oleh ibu-ibu PKK Pangkalan Jati Baru. Mereka cukup antusias dan semangat cukup tinggi atas keingin mereka untuk bisa, hal itu nampak dimana para ibu-ibu PKK tersebut membawa langsung notebooknyallaptopnya sendiri-sendiri (memfasilitasi sendiri perangkat yang dibutuhkan), berusaha mempraktekan kedalam notebook /laptopnya masing-masing. Cukup banyak pertanyaan yang diajukan ataupun keingintahuan ibu-ibu PKK Pangkalan Jati Baru, mereka juga menginginkan adanya tambahan waktu lagi untuk lebih banyak mempraktekannya dan keiinginan mereka para ibu-ibu PKK Pangkalan Jati Baru untuk bisa mengoperasikan sofware tersebut yang merupakan bagian dari teknologi infomasi.

\section{SIMPULAN}

Banyak orang yang meprediksi bahwa 3 aplikasi (word, excel dan power point) yang terdapat pada microsoft office merupakan pembelajaran yang mudah ataupun sesuatu yang umum dan sering dilakukan. Namum kenyataannya dilapangan masih cukup banyak orang yang tidak dapat mengoperasikan ataupun tidak dapat mengoperasikan ketiga aplikasi tersebut dengan benar dan tepat. Selain itu, cukup banyak makalah, karya ilmiah ataupun tulisan-tulisan yang tidak memperhatikan kaidah-kaidah dalam penulisan/ pengetikan yang sebenarnya.

Dalam pelaksanaan pengabdian masyarakat di Kecamatan Cinere kepada ibu-ibu PKK Pangkalan Jati Baru Depok, tim mengalami cukup kesulitan dikarenakan peserta kebanyakan adalah ibu-ibu rumah tangga yang pekerjaan sehari-harinya tidak banyak menggunakan laptop/ notebook, sehingga diperlukan tingkat kesabaran maupun ketelatenan yang cukup mendalam. Sehingga tim tidak dapat memberikan pelatihan ataupun pembelajaran yang tingkatnya lebih tinggi. Peserta (Ibu-ibu PKK Pangkalan Jati Baru) mengharapkan waktu tambahan lagi untuk dapat diberikan pelatihan kembali dalam beberapa hari. Namum dengan keterbatasan tim baik waktu maupun dana yang dimiliki tim kami belum bisa memastikan kesedian.

Walaupun dirasa belum sepenuhnya mencapai target dan luaran yang diharapkan, mengingat ibu-ibu PKK Pangkalan Jati Baru jarang sekali memegang laptop/ notebook ataupun komputer dimana kesehari-hariannya lebih banyak bekerja sebagai ibu rumah tangga, namum demikian kegiatan pengabdian masyarakat ini telah berupaya memberikan kontribusi positif bagi upaya peningkatan pembelajaran komputer. Oleh karenanya atas dasar tersebut kami mengajukan saran dan rekomendasi sebagai berikut:

1. Ibu-Ibu khususnya yang tergabung dalam PKK Pangkalan Jati Baru diberikan waktu/kelas khusus untuk diberikan pelatihan tambahan (waktu terjadwal dan lebih dari 4 kali pertemuan ) dalam pengoperasian word, excel dan power point.

2. Diberikannya tugas secara bergilir kepada mereka para ibu-ibu yang tergabung dalam PKK Pangkalan Jati Baru untuk membuat presentasi, tulisan ataupun dalam bentuk laporan-laporan.

\section{DAFTAR PUSTAKA}

J. K. Debora Meriska Punusingon, Sarah Sambiran. (2018). Peran Lurah Dalam Mengoptimalisasikan Kegiatan PKK di Kelurahan Tingkulu Kecamatan Wanea 
Kota Manado. Jurnal Eksekutif . Fakultas Ilmu Sosial dan Politik Universitas Sam Ratulangi. Vol 1 No.1.ISSN : 2337 - 5736.

Peraturan Daerah Kota Depok Nomor 06 Tahun 2010 Tentang Perubahan atas Peraturan Daerah Nomor 08 Tahun 2008.

Peraturan Menteri Dalam Negeri No 1Tahun 2013 Tentang Pemberdayaan Masyarakat Melalui Gerakan Pemberdayaan Dan Kesejahteraan Keluarga.

T. Suryana and Koesheryatin. 2014. Mengenal Microsoft Office 2013. ISBN . 9786020242095 